\title{
La Educación decimonónica como construcción de resistencias en profesoras
}

\section{The Nineteenth-Century Education as a Construction of Resistances in Female Professors}

\author{
Luis Enrique Meléndez-Ferrer ${ }^{1}$ \\ Universidad del Zulia \\ Facultad de Humanidades y Educación \\ Centro de Documentación e Investigación Pedagógica (CEDIP) \\ Maracaibo, Venezuela \\ lemelendezferrer@gmail.com \\ ORCID: orcid.org/0000-0003-0492-5652
}

Recibido: 10 setiembre 2015 Aceptado: 16 junio 2016 Corregido: 18 junio 2016

\begin{abstract}
Resumen: La educación decimonónica es una construcción social de control cultural del patriarcado que se concreta en la heteronormatividad de la Ilustración. Debatir sobre esta educación implica considerar varios elementos como: enfoques feministas, resistencias y dominación patriarcal. Es importante analizar las visiones que sustentan la educación decimonónica como mecanismo reproductor de resistencias de las profesoras en sus prácticas sociales. Como consecuencia existe un cuerpo referencial con nociones sobre elementos anteriores más la noción visión, como categoría ordenadora del análisis educativo. Este debate se fundamenta en un enfoque cualitativo mediante la convivencia, problematización situacional, la etnografía social, la resignificación conceptual, el interaccionismo simbólico y la discusión sobre feminismos, géneros, mujeres, andragogía y subyugación universitaria. El análisis se estructura en las visiones política, naturalista, religiosa, dominación social y positivismo social. Según estas visiones, la educación decimonónica genera el apego al machismo discriminatorio y nacionalista existente en disciplinas científicas para que las profesoras se beneficien. También refuerza en ellas los gremialismos racistas al ser artefactos útiles, lo cual logra la desigualdad sexista y el separatismo del sistema sexo / género. La educación desvela la civilidad mediante una educación pragmática y descalificativa, acentuando un empoderamiento masculino en las mujeres y el reconocimiento de su discriminación institucional-educativa. Este discurso vislumbra la religiosidad en educación y el miedo a romper esquemas. Además, impulsa a que las mujeres coparticipen del patriarcado positivista con la opresión heterosexual cientificista, instaurando su invisibilidad epistémica y doméstica. Finalmente, la educación refleja a unas profesoras despersonalizadas y robotizadas por la ciencia, al modelar la educación decimonónica, fortaleciendo su productividad rentable y resaltando identidades agencialistas.
\end{abstract}

Palabras claves: Educación decimonónica, resistencias, profesoras.

1 Doctor en Ciencias Humanas. Magister Scientiarum en Educación. Profesor titular e Investigador. Trabaja en el Centro de Documentación e Investigación Pedagógica (CEDIP). Dedicado a la formación en investigación social desde miradas históricas, políticas y culturales con base postestructural, cualitativa y decolonial. Enfocado en comprender las cotidianidades de profesoras universitarias mediante la construcción de estudios feministas, estudios sobre mujeres y géneros en la Universidad del Zulia (Venezuela). Ha publicado artículos recientemente sobre: "El estado y la Iglesia: un espacio existencial para la dominación androcéntrica hacia las mujeres" (Venezuela, 2013); "De la estética binaria a las socioestéticas plurales en encuentros cotidianos entre colectivos íntimos" (Venezuela, 2011); "Enseñar sexualidades, aprender subjetividades: una reflexión desde el contexto educativo venezolano" (Costa Rica, 2009). Asimismo, ha publicado libros referentes a: "Huellas del Estado-nación en las mujeres de la universidad venezolana. Una mirada sociohistórica del discurso de las leyes, iglesia y partidos políticos en las resistencias de las profesoras." (España, 2012); "Condiciones pedagógicas del profesorado universitario: Una mirada sobre el ser, saber y hacer del profesorado de las ingenierías en la profesión académica venezolana." (España, 2012). "A modo de prefacio: un diálogo con Nathalia Jaramillo para pensar un proyecto educativo decolonial desde la pedagogía crítica." (Venezuela, 2012) 


\begin{abstract}
Nineteenth-century Education is a social construction birthed from cultural control of the patriarchy that takes form in the heteronormativity of the Enlightenment Era. A debate regarding this Education involves considering several elements: feminist approaches, resistance, and patriarchal domination. It is crucial to analyze the visions that support the Nineteenth-century Education as female professors' resistance-building mechanism within their social practices. There is, thus, a reference corpus of concepts related to previous notions plus the element of vision, as the organizing category of educational analysis. This debate is grounded on a qualitative approach by means of coexistence, situational problematization, social ethnography, conceptual redefinition, symbolic interaction, and discussion about: feminism, gender, women, andragogy and Higher education subjugation. The analysis is structured within all these visions: political, naturalist, religious, social dominance and social positivism. In accordance to such perspectives, Nineteenth-century Education creates an attachment to the discriminatory and nationalist chauvinism that already exists in the scientific disciplines to pursue female professors' benefit. It also reinforces in these professors the racist guildism portraying them as useful artifacts, which leads to gender disparity and separatism within the sex/gender system. Education unveils civility through a pragmatic and underestimating education, emphasizing a masculine empowerment in women and the acknowledgment of their institutional and educational discrimination. This discourse allows glimpsing religiosity in education and a fear of breaking established schemes. In addition, it drives them to co-participate in the positivist patriarchy by means of the heterosexual oppression of the scientistic, thereafter establishing their epistemic and domestic invisibility. Finally, education reflects depersonalized female professors, robotized by science as they model the Nineteenth-century Education, strengthening their economic productivity and emphasizing their agency-oriented identities.
\end{abstract}

Key Words: Nineteenth-century Education, Resistance, Female teachers

\title{
Acercamiento a la educación decimonónica: Una génesis de resistencias
}

La discusión sobre la educación decimonónica surge de una interpretación constituida en la tesis doctoral, intitulada: Resistencias en las prácticas sociales de profesoras universitarias (Meléndez-Ferrer, 2015a), la cual fortalece los estudios sobre mujeres en la universidad venezolana. El análisis sobre resistencias parte de la múltiple resignificación conceptual, la determinación patriarcal del Estado-nación y desde aportes históricos, políticos y epistémicos de los feminismos. La tesis desmonta discursos educativos positivistas reproducidos en la formación de mujeres, así como en sus prácticas andragógicas al profesionalizarse.

Para este debate se consideran varias temáticas de partida que configuran un amplio contexto hermenéutico en donde se ubican dominios que funcionan como puntos de tensión analítica. La primera temática asumida es la mirada de enfoques feministas que abordan a las mujeres intelectuales (Meléndez-Ferrer, 2014) no como sujetos sino como actoras sociales y como nociones fenoménicas de categorías construidas culturalmente, en donde se corporizan diversas estéticas de poder ${ }^{2}$. Es importante incluir tales enfoques porque instauran aportes

2 La estética es un conjunto complejo de identidades culturales, temporales, de lugares e históricas. Estas identidades son signos que generan identificaciones en pro de construir realidades subjetivas y objetivas, lo cual produce representaciones indefinidas e infinitas sobre los diferentes mundos sensibles en los que existimos e interactuamos. La estética deja de ser entendida de forma única porque son las estéticas, ya que se resignifican de manera plural, diversa y diferente con un sentido amplio de libertad y de semiosis social. De forma contraria, la estética es un mecanismo de modelaje social que determina y somete a la consciencia colectiva en pos de establecer un-gran-orden-social sobre las racionalidades, emocionalidades, corporalidades e interacciones humanas. Las estéticas del poder se institucionalizan como un sistema hegemónico de valoraciones heterosexuales, destinado a la dominación patriarcal de las sensaciones, representaciones e imaginarios, es decir, se naturalizan y sintetizan como discurso político heteronormativo sobre los modos de vivir. 
claves al entender la dominación, así como la forma en cómo se bosqueja el ejercicio del poder dominante en las significaciones e interacciones sociales de mujeres universitarias. Por esto, en la educación decimonónica se desvelan las intersubjetividades, identidades y prácticas socioculturales de las dominaciones performativas, lo cual es puntual al desestructurar la subyugación-y-opresión de las profesoras en sus prácticas educativas.

La segunda temática se visualiza en el análisis de las resistencias (Meléndez-Ferrer, 2012) como proceso vinculante entre tal categoría con el objeto: la educación decimonónica. Esto entiende las subjetivaciones, significaciones compartidas y prácticas sociales desarrolladas por las mujeres profesoras, específicamente lo relacionado con su mundo educacional. Se enfatiza la interpretación de resistencias al convertirse en un enfoque revelador de situaciones, relaciones e imaginarios determinantes sobre el pensar, el emocionar, el convivir y el quehacer de las mujeres intelectuales. La comprensión de tal educación es fundamental al ser considerada como una categoría analítica cristalizada en un discurso ideológico, material, cultural e histórico de resistencias hegemónicas, las cuales delimitan el espacio sígnico-social de las profesoras. Desde la racionalidad machista de la educación enunciada, es urgente reconocer las resistencias que empujan en contra de principios, modelos y formas de una educación monolítica, la cual se trata en este artículo.

Por último, la tercera temática refiere al mismo discurso ideológico, político, óntico, epistémico y pragmático de la educación pensada desde la dominación patriarcal (MeléndezFerrer, 2015b; Meléndez-Ferrer y González Sulbarán, 2015c), la cual posee una base históricocultural de la Modernidad e Ilustración. Se destaca, entonces, el profundizar en dicha educación porque esta se inspira, se constituye en un complejo discurso blindado por el pensamiento positivista, naturalista y teocéntrico monoteísta de la cultura occidental, el cual reproduce y defiende la misma dominación anterior. Este pensamiento se ha instalado como legítimo, hegemónico, homogéneo y universal en pos de subyugar las consciencias, producciones e interacciones sociales que controlan a las profesoras. Se reconoce la urgencia de repensar que el discurso decimonónico es un enfoque que des-cubre estructuras paradigmáticas que se sistematizan e instrumentalizan al mantener la hegemonía tanto de la ciencia como estructura política e ideológica; del método científico como sistema patriarcal lineal, verdadero y único; así como también, del conocimiento científico como producto consensuado, garante, riguroso y válido para conocer una realidad objetivada ${ }^{3}$ y mediatizada por mecanismos predeterminados.

Tras enunciar las temáticas iniciales que impulsan esta discusión, el propósito central es analizar las visiones que sustentan la educación decimonónica como mecanismo reproductor

3 La realidad objetivada visibiliza una noción de objetividad (entre paréntesis), planteada por Humberto Maturana. Refiere a la objetividad en la validación de explicaciones científicas. Esta debe ser puesta "entre paréntesis" porque el conocimiento es una construcción en el lenguaje dirigido a captar una realidad independiente de las observadoras (las profesoras). Este concepto tradicional es la objetividad trascendental. La objetividad (entre paréntesis) se sustenta en el determinismo estructural de sistemas vivos, relacionados con su entorno en las posibilidades de su constitución estructural. Lo percibido del mundo exterior corresponde a un ensamblado hecho por las mujeres intelectuales en su función de observar a partir de sus estructuras y tiene que ver con sus historias de cambios estructurales, más que con el agente que estimula los sistemas sensoriales que, en sí mismo, no tiene el poder de impulsar los cambios de estado que tuvo el sistema que observa. La aprehensión objetiva del entorno es imposible por la misma constitución estructural de seres vivos, que solo procesan de su entorno aquello que su estructura permite. Se requiere poner (entre paréntesis) la objetividad, sino hay que aceptar la fuente de validación de conocimientos que proviene de lo que no depende de las profesoras en su actitud observadora. La objetividad no se necesita al montar una explicación científica. Lo que sucede es producido por las mujeres intelectuales observadoras en su praxis de vivir como condición empírica primaria. Esta (objetividad) expone una existencia generada mediante las distinciones de las profesoras observadoras. 
de resistencias de las profesoras en sus prácticas sociales. Así, la discusión contempla visiones convertidas en caminos epistémicos y hermenéuticos cruzados en pos de visibilizar la constitución de la educación decimonónica y la manera en que esto actúa como sistema generador de resistencias en las prácticas sociales de las profesoras. Sin ánimos de crear una interpretación absoluta ni abarcadora, se plantean visiones histórico-culturales que estructuran este debate, a saber: la política, la naturalista, la religiosa, la dominación social $\mathrm{y}$ el positivismo social.

\section{Referentes conceptuales sobre la educación decimonónica}

Un elemento importante refiere a los enfoques feministas de cara a ser interpretados desde varias miradas teórico-prácticas. En principio, son perspectivas críticas, reflexivas y epistémicas construidas para agrupar las diversas teorías feministas. Así, se valoran las diversas estructuras filosóficas e ideológicas que explican y fundan con principios teóricos la variada tipología existente de feminismos, independientemente de que sean contradictorios o que apunten a fenómenos sociales, políticos, epistémicos, ónticos, históricos, económicos e ideológicos diferentes. Los diversos enfoques pueden ser: sufragista, liberal, igualdad, ilustrado, hegemónico, institucional, académico, internacionalista, diferencias, anarquista, radical, socialista, ecofeminismo, neofeminismo, cultural, postmoderno, contrahegemónico, negro, postcolonial-decolonial, indígena, teológico, autónomos, amerindianos, hasta ahora. Los enfoques feministas son discursos epistémicos entretejidos dispuestos a sustentar bases políticas, filosóficas e ideológicas que se materializan en cuerpos críticos, analíticos y reflexivos indispensables para la acción feminista. La segunda postura al comprender los enfoques feministas se plantea como las planificaciones, movimientos sociales, acciones coordinadas, interdependientes, disgregadas o anti-institucionalistas que se generan en los colectivos sociales y entre estos, en pro de luchar, defender, cambiar o eliminar una estructura dominante en la sociedad. Por esta razón, tales enfoques se notan como las interacciones productivas dirigidas hacia el cambio social antipatriarcal. En fin, los enfoques feministas son discursos prácticos entrelazados e interesados en concretar y operacionalizar las estructuras metódicas, procedimentales y autoevaluativas que se configuran en cuerpos pragmáticos, intervencionistas, disruptores, desestructuradores e irreverentes; frente a los mecanismos dominantes del patriarcado, lo cual da la visibilidad indispensable para la transformación feminista en el Estado.

Otro elemento clave es que esta discusión especifica el campo de análisis diverso sobre las resistencias consideradas -en términos generales- como el arte de existir, las fuerzas del poder, las contradicciones, los puntos de tensión, las polaridades y como el sustento de estrategias y tácticas en el ejercicio del poder. Así mismo, son categorías sustantivas al entender los mundos intersubjetivos e interactivos encarnados en las historias socioculturales de los modos de vida los colectivos humanos. Las resistencias son construcciones universales, es decir, muestran la universalidad de muchas voces que parten de diversas perspectivas conflictivamente entrecruzadas, las cuales surgen a partir de versos (discursos) filosóficos, epistémicos, ónticos, axiomáticos, prácticos, sociales, culturales, políticos e ideológicos.

El análisis sobre resistencias en su gestación desde la educación decimonónica incluye los divergentes aportes de los feminismos, los estudios sobre los géneros y las mujeres, las 
prácticas productivas, la profesionalización, la profesión académica, la institucionalidad universitaria, entre otros. Esta construcción enfoca las resistencias como un objeto de análisis fundamental, contenedor de nociones encarnadas en las siguientes dimensiones temáticas: resistencias, mujer, profesoras, modos de vida y formación de profesoras; las cuales circundan alrededor de la educación decimonónica. Lo anterior es un camino en pro de entender las prácticas sociales de las profesoras en su mundo universitario, desde una mirada identitaria. Así se profundiza en el debate histórico-epistémico sobre las resistencias de las mujeres intelectuales. Se requiere, entonces, explicar las resistencias emplazadas en las prácticas sociales interpretadas como un espacio óntico, objetivado e identitario para comprenderlas como procesos de construcción cultural en la universidad y en los cuerpos de mujer. También, se necesita especificar el contexto relacional en donde se producen las resistencias. Por eso, las prácticas de las mujeres intelectuales se reconocen en un contexto global e interrelacional en donde se genera las resistencias.

Por otro lado, el tercer elemento básico es la dominación patriarcal, esbozado por Meléndez-Ferrer y González Sulbarán (2015c), quienes la consideran como práctica identitaria constituida por el discurso patriarcal. Este discurso refiere al silenciamiento de la mujer, la mutilación del cuerpo para ser aceptado por alguien más (específicamente, según la aprobación de una figura masculina), la desigualdad de género y la castración sexual. Dicho discurso establece que es necesario seguir el canon de belleza impuesto por la sociedad gobernada por la masculinidad, así signifique mutilar el cuerpo o realizar grandes sacrificios para encajar en ese ideal de belleza creado por la sociedad patriarcal. Por eso, la dominación como fundamento del discurso patriarcal fomenta que la mujer debe ser educada para resolver o facilitar los problemas de los hombres.

Aunadamente, Meléndez-Ferrer (2015b) propone que la dominación patriarcal se basa en la visión absolutista de la dominación masculina sobre la mujer, panoptiza ${ }^{4}$ la norma, sanción y el castigo de sus acciones universitarias mediante la rigurosidad e inmutabilidad de la ciencia moderna. Por eso, plantea que la dominación patriarcal considera varias situaciones simbólicas-materiales de opresión. La primera situación de subyugación es que ellas mismas, por reproducir los estereotipos, están sujetadas a relacionarse con otras personas a quienes les deben exigir esas mismas etiquetas discriminatorias; con ello evitan la oportunidad de

4 La acción panóptica asume el concepto del panóptico. Tal acción domina las corporalidades, racionalidades, emocionalidades e interacciones sociales de las personas, en términos colectivos e individuales, en especial a las mujeres en el mundo profesoral. El efecto troncal del panóptico o ideología del panoptismo es inducir en las profesoras junto con el colectivo social, un estado consciente y permanente de vigilancia que garantiza el funcionamiento automático del poder. El poder no requiere ser ejercido de forma efectiva, visible, directa en cada momento, puesto que las mujeres intelectuales no deben identificar ni pueden saber cuándo, quiénes ni tampoco se les vigila y cuándo no. El panóptico debe producir un "sentimiento de omnisciencia invisible" sobre las profesoras en su colectivo universitario, es decir, en todas partes y en todo momento, las mujeres intelectuales son observadas con ánimos de evaluar, controlar y castigar su ser, estar y hacer en las funciones universitarias. El panoptismo como ideología y práctica social naturalizada y normada configura un modelo abstracto de una sociedad disciplinaria, la cual crea dispositivos panópticos que se viabilizan política e ideológicamente y estos se hacen factibles en habitus en las instituciones del Estado, así como en las estructuras sociales: familia, escuela y comunidad. Lo panóptico es un mecanismo polifuncional, enfocado en que las o instituciones del Estado (la universidad) tiene la necesidad imprescindible de materializar la observación como eje central para que puedan funcionar de manera correcta, civilizada y heteronormativa. La práctica panóptica es la subyugación sobre la existencia mediante una constante mirada ante el ser, sentir y hacer de las mujeres en su identidad de profesoras. El panoptismo es una técnica de control de racionalidades, emocionalidades, corporalidades e interacciones sociales de las mujeres en la universidad. Lo panóptico es la utopía de un poder que configura una sociedad vigilada e idealizada, en términos contextuales la sociedad universitaria. Tal poder utópico es el panoptismo, pues él convive en una sociedad en donde reina la vigilancia oculta de la cultura científica, la cultura heterosexual y decimonónica, en este caso especial, una mirada oculta sobre las profesoras y sus prácticas universitarias. 
incorporar (basadas en una lógica depredadora-negativista de la otredad) a otras personas, quienes pueden ser pertinentes y necesarias en sus funciones universitarias.

La segunda situación de dominación de tal discurso es que las mujeres intelectuales crean la misma lógica sexista y racista del cientificismo patriarcal; establecen, así, una expresa competencia disciplinaria, lucha de poder, lucha por la representatividad de gobierno entre subgrupos en las mismas comunidades universitarias. Así, pues, tal dominación es un sistema troquelador, predeterminado, jerárquico y procedimental que actúa sobre el quehacer humano. Entonces, la lógica de subyugación mencionada intenta siempre reproducirse y circular como un sistema vivo, controlado por grupos dominantes de autoridad-poder sobre las personas, acentuadamente, con efecto en la vida de las mujeres universitarias.

El cuarto elemento relevante es entender que la visión es un camino que supera el sesgo individual con el fin de producir conocimientos. Este sesgo es un modo operativo naturalizado para legitimar el poder de la individualidad disciplinaria, así como también es una forma tubular de crear interpretaciones limitadas sobre las realidades sociales. La visión se enfrenta al enquistamiento mental y práctico invasor del pensamiento de la Modernidad ilustrada. Toda esta discusión en cuanto a la visión se relaciona con los planteamientos de Cray (2008, p. 179-180), quien expone que "El colapso de la cámara oscura como modelo de la condición del observador formaba parte de un proceso de modernización”. Esta línea de pensamiento es considerada un enfoque fundamental para introducirse en la comprensión sobre las nociones en torno a las visiones de la educación decimonónica en su función de crear resistencias en las profesoras. Por eso, es un dispositivo para eliminar los límites representacionales y hermenéuticos que ha demarcado la Modernidad al enfrentarse a la comprensión de objetos sociales cotidianos y a las profesoras en su vida universitaria.

Desde el enfoque de Cray (2008), la visión ha estado “... siempre dentro de un terreno de experimentación altamente delimitado" (p. 179-180). Por tanto, se quiere romper esos límites planteados. Con esta intención, la visión sobre la educación decimonónica está llamada a ser un dispositivo para flexibilizar o eliminar los límites representacionales y hermenéuticos que ha demarcado la Modernidad eurocéntrica, al enfrentarse a la comprensión de objetos sociales cotidianos y a las personas, con atención especial, a la noción sobre educación y resistencias en la vida universitaria de las profesoras. La visión reconoce la existencia de un discurso hegemónico y alienante sobre una seudolibertad de quienes observan, con ojos panópticos y castrantes. Así implanta la necesidad de liberar las perspectivas de observación y de liberar los cuerpos observadores, refiriéndose a las miradas-sensibilidades de las mujeres académicas. Lo anterior instaura complejamente conocimientos sobre sí mismos en cuanto a su entorno social y su lugaridad. Se resalta una noción de visiones para construir una actitud observadora intuitiva más independizada de las sentencias, axiomas, principios contenidos en teorías y métodos cientificistas. La visión es una aproximación para resignificar la percepción naturalista, sensorial y reduccionista de la modernidad. De allí, se defiende una percepción sígnica sobre la educación decimonónica que libera los enfoques epistémico-disciplinares. Todo esto desvela nuevas lógicas e interacciones sociales productoras de conocimientos con mayor disposición al transdiálogo de saberes.

Finalmente, la visión es un mecanismo sociocultural que supera la linealidad epistémicaóntica-filosófica, la rigidez teórico-metodológica, las perpetuaciones de interpretaciones, el 
afianzamiento de saberes, la identificación única de lo que existe afuera de la mente, la inmovilidad de perspectivas analíticas, entre otros aspectos. La visión sobre la educación decimonónica como generadora de variadas resistencias surge al proponer nuevas prácticas sociales que permiten 'llegar a otras orillas' en las realidades sociales, en las que emerge la fuerza impuesta por cambios sociales de la universidad y la sociedad. Este elemento es una construcción política e ideológica que invita a trasgredir modelos estáticos del pensamiento, así como también las tradiciones culturales del contexto local. Por tanto, la visión legitima nuevas formas estéticas sociales, científicas e institucionales que establecen diferentes reflexiones, lo cual instala orientaciones legítimas, democráticas y confiables para generar conocimientos/saberes relacionados con las resistencias de las profesoras.

\section{Aspectos metodológicos}

El propósito expresado se concreta mediante una episteme teórico-metódica cimentada en la investigación cualitativa. Por esto el debate sobre la educación decimonónica se aborda desde un primer proceso que teje una convivencia con profesoras trabajadoras en la Escuela de Educación. Dentro de esta coexistencia se observan las funciones académicas (docentistas) y roles laborales desplegados en sus reuniones departamentales, asambleas profesorales, eventos científicos e, igualmente, en la gestión universitaria. Por otro lado, se identifican las significaciones y prácticas educativas en documentos referentes a teorías sobre la educación, en general. Con estos contenidos se estudian críticamente las cotidianidades universitarias y situaciones educacionales conflictuadas en la sociedad venezolana, lo cual muestra discursos educativos contemporáneos e históricos. En este ambiente discursivo se comparten algunas tendencias sobre las intenciones educacionales de tales documentos en su ser-y-quehacer cotidiano con las profesoras.

Un segundo proceso madura las percepciones sobre las características que problematizan la educación decimonónica como categoría discursiva que activa las resistencias en las prácticas sociales de las profesoras universitarias. Para esto se instaura un conjunto de discusiones grupales en la línea de investigación "representaciones, actores sociales y espacios de poder" (RASEP) y en la de "sistemas, políticas y actores de la educación superior" (SPAES) adscritas a la misma Facultad. Esta interacción social se focaliza en las ideas centrales sobre la educación y las prácticas andragógicas que desarrollan resistencias en vinculación con las prácticas socio-productivas, como objeto de análisis más delimitado. Igualmente, se entretejen diálogos sobre los feminismos, los estudios de géneros y los estudios sobre las mujeres, como grandes discursos importantes para entender los imaginarios, objetos e interacciones liberales de la universidad escolástica venezolana, currículos académicos y prácticas profesionales educativas. En consecuencia, se le otorga relevancia a tales temas desde las perspectivas asumidas por las profesoras y no con una visión genérica.

El tercer proceso desarrolla una perspectiva con principios de los estudios de género, específicamente, enfocados en la noción del género femenino y de mujer. Así, se comprende las identidades y roles de géneros expresados en discursos epistémicos y en prácticas educativas de las profesoras. Se discute, entonces, sobre la configuración conceptual y delimitación histórico-material de los géneros determinados por la educación decimonónica, 
lo cual se concreta en el diálogo con estudiantes de educación en tal Escuela. Las actividades referidas permiten conversar sobre los feminismos y los roles de las mujeres intelectuales en el contexto de la formación profesional. También, en las actividades se reconocen las prácticas andragógicas, con la intención de analizar la vida cotidiana de las profesoras desde una visión colectiva y transdiciplinar. De manera simultánea, se despliega un análisis sobre el contexto de dominación epistémica, política e ideológica creado en la universidad y sociedad venezolana. Igualmente, se interpretan, de forma crítico-reflexiva, los modos de vida socio-educativos de las profesoras universitarias mediante yuxtaposiciones con elementos conceptuales-argumentativos reflejados desde los estudios de géneros. Esta interpretación desvela temas claves que sustentan las prácticas educacionales de las mujeres intelectuales en la universidad y fuera de ella. Todo lo anterior consolida más el discurso descriptivo sobre el estado del arte de la educación decimonónica en su acción reproductora de resistencias en las prácticas sociales de tales actoras.

La convivencia social planteada se sustenta en la etnografía social, tomando en cuenta los estudios de casos (Rodríguez, Gil y García, 1996) y la etnografía en contextos escolares (Aguirre, 1995). Se descubren, a su vez, variados significados sobre la vida profesoral mediante conversaciones espontáneas y se toman como referencia significaciones acerca de la educación, las resistencias, las prácticas educativas, la universidad, con especial atención en las visiones enfocadas anteriormente. Esta discusión surge por la reflexión crítica frente a los aportes teóricos de la educación decimonónica puestos en un diálogo situacional, a partir de la observancia constante del protagonismo de las profesoras. Por tanto, se asume una visión interpretativa hacia las intersubjetividades emergentes en las concepciones de educación, resistencias, prácticas socio-productivas, formación profesional, universidad, dominación científica, como base para entender los condicionamientos ideológicos que someten a las mujeres intelectuales, así como en pro de comprender las interacciones socio-laborales de la comunidad profesoral, que crea una lucha política e ideológica en sus vidas universitarias, bien sea a su favor o en su contra (Denzin y Lincoln, 1994; LeCompte, 1995; Rodríguez, Gil y García, 1996).

Por otro lado, se incorporan los principios influyentes sobre la vida académica, política e institucional de las profesoras en su mundo cotidiano universitario. Entonces se considera que las resistencias, las mujeres y sus vidas en su condición de profesoras, las prácticas sociales, el contexto universitario son aspectos conformadores de la educación decimonónica como fenómeno articulado que se cimienta en múltiples significados sociales. Dichos aspectos se constituyen por diversos fenómenos situacionales que interactúan en la educación decimonónica con cualidades "polifenoménicas", entendidas desde miradas plurales (Contreras, 2005; Heidegger, 1927; Quesada, 2003, p. 359). Estas cualidades polifenoménicas de la educación pueden estar identificadas por diversas cualidades, por ejemplo, la política, la económica, la social, la filosófica, la local-territorial, la ideológica, la religiosa, la gubernamental, la institucional, la categorización de los géneros, entre otras. Las cualidades polifenoménicas se basan en una abstracción referida a la intra-e-intersubjetividad social de pensamientos, paradigmas y hechos educativos, en donde fluyen procesos-productos que hablan sobre las profesoras. Por tanto, se expone la adecuación de signos contextuales-situacionales en pro de entender la forma en que las mujeres intelectuales, los documentos revisados y el equipo de coinvestigadoras conforman un todo que permite construir las realidades sociales (Berger y 
Luckmann, 1979) en torno al discurso de la educación decimonónica y su acción productiva de resistencias encarnadas en dichas protagonistas sociales.

Este cuerpo comprende la educación decimonónica en el marco de la gestación sígnicacultural de resistencias, desde la aproximación que permite el interaccionismo simbólico, expuesto por Mead (1923), Doménech, Iñiguez y Tirado (2003) y la interacción social comunicativa (Calonge y Casado, 2001). Todo esto materializa la observación participativa e interpretativa. A su vez, se vislumbra, textual-contextualmente, la emergencia de significados que hablan en los documentos mencionados, los cuales se revisan en pos de conocer diversos aspectos fundamentales sobre las significaciones acerca del pensamiento educacional ilustrado, así como de las resistencias creadas por tal episteme. Así, se construye un conjunto de categorías fundamentales: visión política, visión naturalista, visión religiosa, visión dominación social y visión positivismo social, con la finalidad de estructurar el debate sobre la educación decimonónica.

\section{Discusión y resultados: Visiones sobre la educación decimonónica}

\section{Visión: Política}

Según Bowen y Hobson (1979), se revela que la educación general, en la época helénica, está fundamentada en siete artes liberales. En ella existen cuatro áreas referentes al contenido del conocimiento: aritmética, geometría, astronomía y armonía. Dentro de estas artes hay tres métodos que organizan dicho contenido: el dialéctico o lógico, el retórico y el gramático. Así se instaura una visión política de la educación configuradora de una estética masculina de conocimientos basada en una lógica abstracta-simbólica; lo cual excluye a las mujeres intelectuales de espacios científicos para que participen más en las ciencias sociales y menos en las básicas. Este discurso educativo crea una estética masculina de conocimientos fundada en un lenguaje y la oralidad. Todo esto promueve que las profesoras tengan más oportunidad al dedicarse a producir conocimientos sobre la lengua, aunque estén sujetas a epistemes lingüísticas. La propuesta de Jean-Jacques Rousseau (1712-1778) establece una filosofía educativa que amenaza la filosofía de la educación privada (entendida como una interacción exclusiva, elitista, sexista e individualizada), la cual es defendida por Platón y Aristóteles (Bowen y Hobson, 1979). Entonces, la educación expone la apertura para que las mujeres interactúen en la educación formal. Sin embargo, ellas se benefician de los derechos civiles que privilegian, más que todo, a los hombres. Así, las profesoras se han aprovechado de ventajas civiles de la burguesía defendida por el ideario rousseauniano, muy a pesar de que el protagonismo socio-político lo sigue llevando el cuerpo e ideología masculina.

Por tanto, se visibiliza la productividad de las profesoras en la sociedad venezolana, a pesar de que tal rendimiento se concibe en la episteme patriarcal y no aprovechan la oportunidad en pro de construir huellas significativas a partir de intersubjetividades de lo femenino y del ser mujeres. La episteme y el desaprovechamiento de generar conocimientos desde la epistemología de mujeres se evidencia, por ejemplo, en los diferentes artículos científicos, en las ponencias de eventos académicos, en los trabajos de ascenso profesoral, en 
los trabajos conducentes a grado profesional y postgrado. En la productividad académica se acentúa una preferencia en temas gerenciales, curriculares, disciplinares e institucionales. Dentro de estos trabajos, las profesoras hacen relevancia a varios aspectos, tales como: la formación organizacional; la estructuración lineal, generalizada y competitiva de los pensa de estudios; la defensa de la monodisciplinareidad; la importancia del conocimiento eurocéntrico y le restan valor al conocimiento emergente de comunidades locales; la legitimación y perpetuación de modelos de organización universitaria con criterios de internacionalización, efectividad, rentabilidad, eficacia y eficiencia determinada por la ideología tecnocrática y economicista. En tal productividad ellas excluyen temas sobre los feminismos, realidades cotidianas de las mujeres y temas asociados con las diversas luchas sociales, políticas, económicas e ideológicas en pos de restarle fuerza a la dominación patriarcal y capital que oprime a la sociedad venezolana. En relación con esto, Baczko (2000), visibilizando los aportes de Charles Maurice de Talleyrand-Périgord (1754-1838), propone que la educación amplía la libertad civil, con la finalidad de garantizar una libertad política en la estructura social. La educación decimonónica permite que las profesoras desarrollen su alcance socio-profesional, a pesar de tener persistentes limitaciones disciplinares, partidistas, políticas e institucionales en pos de expandir su visibilidad productiva. Este mismo autor considera que la educación dirigida a las mujeres es algo muy simple. Por eso las profesoras son consideradas como el "depósito" de estereotipos socio-culturales, porque ellas encarnan la función profesoral como una opción profesional desestimada, débil, maternal y malamente patriarcalizada por una feminización traidora y automisógina ${ }^{5}$.

Desde otra perspectiva, la educación heteronormativa se basa en la visión política del Estado de bienestar y el Estado benefactor, la cual implica que las mujeres intelectuales han sido personas protegidas por la gratuidad del Estado. Esto desarrolla un espíritu proclive a la acción educativa, así como también le concede la posibilidad de ser actoras seleccionadas por tal formación. Lo anterior las ubica en un escenario de privilegio socioeconómico y de desigualdad de condiciones, al formarse con respecto a otras mujeres no universitarias. Las profesoras aún siguen aventajándose de tal gratuidad, concretada por la misma universidad al continuar con su formación profesional permanente. Para Baczko (2000), lo anterior se fundamenta en las ideas de Marie Jean Antoine Nicolas de Caritat, Marqués de Condorcet (1743-1794), quien configura una educación como una obligación gratuita del Estado, la sociedad, los poderes públicos e instituciones en pro de liberar, perfeccionar e igualar a los "ciudadanos" (con una connotación masculina y de género universal).

La educación se basa en el nacionalismo del siglo XX, se origina un discurso entre razas,

5 La misoginia y automisoginia es la aversión hacia las mujeres intelectuales, la falta de confianza de otros en ellas y la desvaloración en ellas mismas. La misoginia se manifiesta a través de la denigración, discriminación, violencia contra las profesoras y su cosificación sexual de las diferentes mujeres en sus funciones universitarias, así como, en su participación en el gobierno universitario. La misoginia es base de prejuicios e ideologías sexistas e igualmente, fundamenta la opresión de las mujeres intelectuales en las sociedades dominadas por hombres y por el pensamiento heterosexual-heteronormativo. La misoginia se revela desde bromas con la pornografía, violencia y sentimiento de odio hacia su propio cuerpo al que las profesoras son instruidas a sentir, mediante una educación machista y autodiscriminatoria. También, la misoginia es practicada por las profesoras hacia su autoconcepto y prácticas sociales e igualmente en contra de otras mujeres no universitarias. La misoginia es un sistema ideológico o de creencias que ha acompañado a las sociedades patriarcales o dominadas por hombres, el cual continúa colocando a las mujeres intelectuales en lugares subalternos con poca posibilidad de ejercer el poder o de toma de decisiones, sobre todo, en la universidad. Las mujeres han interiorizado su papel como chivos expiatorios de la sociedad, influenciado por su objetivación en los medios de comunicación y en la cultura científica, a través de una cultura de odio y autodesprecio hacia el cuerpo, las ideas, las emociones e interacciones de las profesoras. 
así como también se utiliza como mecanismo de poder y control a la población (Vázquez y Pérez, 2012). Con esta mirada, tal educación hace que las mujeres intelectuales reproduzcan el ideario nacionalista e ilustrado, al momento en que se distancian de las personas que no han sido formadas académicamente ni que pertenecen a grupos/clases del poder científico. Esta educación las obliga a replicar una ideología nacionalista, porque mantiene un discurso explicativo-apegado al patriarcalismo cientificista, generador de un racismo epistémicosociocultural.

Siguiendo el mismo pensamiento, se expone una educación promotora de la separación física e ideológica de la ciudadanía como concepto unificante e ilustrado, en pro de configurar una realidad polarizada y heterosexual entre una ciudadanía republicana y una ciudadanía pobre. Por tanto, la educación decimonónica incita a que las profesoras refuercen un separatismo ideológico, único, de género, disciplinario e intelectual en las prácticas universitarias. Lo anterior emerge cuando se excluyen visiones plurales sobre el mundo controvertido existente en posiciones políticas, lo cual condiciona las interacciones socioproductivas de las profesoras al omitir, psicolingüísticamente, a las personas que hablan otras lenguas nativas y al valorar la productividad de las comunidades indígenas. El separatismo surge en el momento en que ellas discriminan a quienes no están entre los estándares sexuales aprobados por el género heterosexual-dicotómico: mujer vs. hombre; y cuando prefieren al estudiantado con mayor rendimiento académico y disposición a la intelectualidad. Finalmente, el separatismo ocurre al tiempo en que las actoras mencionadas establecen gremialismos disciplinares interesados en resguardar el conocimiento doxo o las propias creencias, técnicas científicas, etc.

A la luz de Camps y Giner (1998), la educación promueve un sentido liberal para la democracia, ante lo cual se requiere la cooperación y solidaridad en la convivencia social. La educación decimonónica concibe a las mujeres intelectuales como sujetos-sujetados al modelo liberal de una democracia más representativa que participativa en la universidad. Dicho fundamento educativo hace que las profesoras se asuman como productos históricomateriales, con el propósito de instalar políticas democráticas de Estado, que incluyen al mundo escolar, profesional y laboral. Todo esto las acerca a construir una convivencia en la que son reconocidas como protagonistas de la solidaridad social.

Para Follari (2008), la educación es un bien transable, una función no regulable ni por la ley del Estado, mucho menos sometida por los mandatos del mercado. Esta educación visiona que las profesoras encarnan ambas perspectivas sociales, políticas y económicas del contexto venezolano. Por tanto, la educación moderna evidencia resultados de políticas educativas ampliadas con miras a visibilizar a las mujeres en el mundo intelectual y, por otro lado, para mostrar los intereses profesionales impuestos por el gran orden imperial del profesionalismo económico.

Pateman (1996) vislumbra una educación fundamentada en el liberalismo político, social, económico e ideológico, la cual se fortalece con el patriarcalismo disipado en la distribución de poder en lo privado y lo público. Consecuentemente, la educación decimonónica dibuja a las mujeres intelectuales como profesionales y ciudadanas, quienes separan lo que el ser humano debe ser-sentir-pensar y hacer en el mundo tanto cultural como doméstico. Es decir, están sometidas por principios ónticos que dominan y organizan moral, ética e ideológicamente sus prácticas productivas, mediante el gran-orden social de cuerpos, creado 
por el patriarcado. Aunadamente, Tomás i Folch (2011) manifiesta que, desde la mirada de John Stuart Mill (1806-1873), la educación reconoce las diferencias entre la categoría género, y la responsabiliza de la desigualdad. Por esto la educación heteronormativa considera que las mujeres intelectuales son sujetos-sujetados a significaciones diferenciadoras en cuanto a la identidad del género heterosexual, y logran su autoconcepción desigual ante otros colectivos de mujeres con identidades de géneros sexodiversos. La educación considera que ellas reproducen concepciones aplicadas en sus relaciones socioeducativas. Por tanto, el patriarcalismo diferencial de la identidad y práctica del género, como categoría heterosexual, acentúa una desigualdad en espacios e interacciones educativas. La educación decimonónica visiona que las profesoras están supeditadas a la visión de mundo-político impuesta por el Contrato Social, ante el cual debe construir un concepto y práctica de seudo-libertad. De por sí, este Contrato no maximiza un concepto civil de mujer libre. Con lo anterior, se funda que la educación se cimenta en el Contrato Social como meta-relato de la moderna obligación política, en el concepto de hombres libres y de maximizar la libertad (De Sousa Santos, 2004).

Bowen y Hobson (1979) proyectan que la Ilustración impulsa una complejidad de la educación por el condicionamiento ejercido sobre el comercio, tecnología y ciencia. Esto instaura una resistencia en las escuelas con la interacción de acoplarse al desarrollo filosófico, científico y tecnológico de la sociedad. La educación burguesa implica que las profesoras estén en constante demanda profesional, académica, presión social y exigencia institucional para entenderse y posicionarse como actoras-clave en la producción capitalista de la ciencia y economía occidental. Así se logra su alienación por el efecto de una ideología tecno-productiva de la ciencia. Se desarrolla, entonces, la visibilidad que favorece más un capital patriarcal que un potencial liberador de subjetividades propias de las mujeres. Esta educación visualiza que las mujeres intelectuales generan resistencias con miras a oponerse a la dominación capital y patriarcal desplegada por el discurso cientificista e institucionalista. Lo expuesto aborda temas marginados y estigmatizan-discriminan a las profesoras por no pertenecer a grandes e importantes grupos poderosos que controlan el modo colonizador político-social de hacer ciencia.

Aunado a eso, Morales (1796) vislumbra la existencia de una educación repetitiva de modelos morales delimitados por epistemes extranjeras. La educación decimonónica condiciona a las profesoras para que valoren más y se apropien de modelos epistémicos profesionales, científicos, educativos. Esos modelos son creados desde otras lugaridades con la intención de reproducirlos en sus prácticas universitarias. Todo esto coloniza las racionalidades, emocionalidades, corporalidades e interacciones sociales emergentes en nuestra-América, institucionalizando la pasividad de las profesoras con el fin de ensamblar nuevos paradigmas de conocimientos y saberes sociales. Según Vázquez y Pérez (2012), se vislumbra una educación creadora del gran orden civilizatorio. Este planteamiento esboza una educación heterosexual que obliga a las mujeres intelectuales a someterse al gran discurso que ordena prácticas intersubjetivas de los colectivos institucionales del Estado, sobre todo, las educativas. Lo expuesto modela las subjetividades civilizatorias que resaltan al paradigma de hombre como ciudadano heterosexual y hegemónico. Por esto, la perspectiva ilustrada de la educación las condiciona a reproducir principios políticos, sociales, económicos, profesionales e institucionales que sustentan la práctica cientificista y elitista necesaria para legitimar el blanqueamiento y racismo civilizatorio. Dicha reproducción se origina desde las bases que cimientan los grandes 
conceptos e interacciones educativas en la universidad. En efecto, se producen identidades diferenciales y jerárquicas entre los colectivos humanos, específicamente, en el interior de los grupos de mujeres intelectuales participantes en la universidad.

La educación es la ideología creada para que las profesoras se subyuguen a tradiciones culturales con perspectivas contradictorias. En las perspectivas existen fundamentos que, por un lado, liberan y, por otro, oprimen las formas del ser, sentir, pensar y hacer del ser humano. Sin embargo, las contradicciones consolidan un sistema naturalizador del ser humano desde tres dimensiones: biológica, teológica y civilizatoria-burguesa; las cuales confluyen en un mismo sistema normativo buscando el castigo y vigilancia de prácticas productivas de las mujeres intelectuales. En relación con lo planteado, Martínez (2006) concibe que la educación se funda en la pedagogía humanística en la que existen contradicciones entre la consciencia feudal y el modernismo, a partir de esto se impone un modelo de naturaleza humana. Con la mirada de esta autora, la educación se apoya en reformas impulsadoras de la educación nacional (el Nacionalismo), es decir, en una educación popular, estatal, obligatoria, laica, cimentada en un espíritu burgués. Así, Baczko (2000) expone el relevante aporte de Marie Jean Antoine Nicolas de Caritat, Marqués de Condorcet (1743-1794), quien propone que la educación tiene un sentido utilitarista de la visión, misión y beneficio. Es decir, educar para ser-hacer cosas útiles y con la intención de gozar de esos logros; aspecto que les otorga deberes y derechos. Tales ideas promueven una educación en donde las profesoras son producto de reformas educativas, jurídico-legales e institucionales apalancadas por movimientos sociales, políticos y eclesiásticos del Estado-nación. Además, las mujeres intelectuales son agentes político-ideológicas reproductoras del nacionalismo, mediante la realización de prácticas productivas, a saber: la construcción de modelos epistémicos, científicos y tecnólogos globales, la gerencia de universidades con modelos jerárquicos decimonónicos, la interacción e integración de instituciones eclesiásticas para la participación social. Todo esto se basa en la exclusión, sexismo y dominación del ser humano en la universidad.

\section{Visión naturalista}

La mirada de Bowen y Hobson (1979) considera que ya desde la educación romana se refuerza el ser práctico y el desarrollo de la capacidad instrumental de la retórica y la oratoria como base de la política. La educación decimonónica contempla a las profesoras como actoras pragmáticas de un capitalismo que rige los paradigmas científicos replicados en la universidad. Por esto, ellas se forman y aplican la profesionalización desde una perspectiva tanto tecnocrática, reguladora, sistémica como economicista, estableciendo una política civilizatoria del saber-conocimiento. Inspirada en Rousseau (1973), la educación vislumbra a las mujeres como seres útiles para educar al hombre infante y para que estén sujetadas a ser: amante, honrada, cuidadora y aconsejadora del hombre. Todas estas cualidades implican una educación Ilustrada, por lo que se defiende que las profesoras sean profesionales y agentes institucionales (empleadas) quienes deben desplegar, con mayor expresión, las actitudes andragógicas con miras a replicar un modelo materno, de cuidado y más afectivo en la actividad docente. En este sentido, se legitiman como protagonistas al ofrecer una educación pragmática, pero sensible al estudiantado, pues existen muchas mujeres que conciben al 
colectivo estudiantil como personas inmaduras, inexpertas, infantiles y en crecimiento tanto social, académico, profesional como laboral. Para ellas, al estudiantado es necesario sobreprotegerlo y controlarlo mediante la formación humana.

Con la perspectiva de Martínez (2006), la educación rechaza el sentido escolástico, al incorporar a las ciencias y a las artes, aproximándose a cambios sustanciales en los contenidos y métodos de enseñanza. En el tiempo renacentista, la educación rescata el sentido clásico, evitando las innovaciones educativas y reforzando el conservadurismo del status quo de la educación (Bowen y Hobson, 1979). Se asienta, entonces, una educación burguesa donde las profesoras son personas intelectuales, quienes muchas veces sabotean su amplitud intelectual, porque desvaloran ciertas fuerzas políticas, sociales, científicas, religiosas, institucionales e ideológicas que renuevan los modelos teórico-metodológicos instalados en pro de regular sus prácticas productivas. Sin embargo, se mantiene una estética estática o se realizan cambios superficiales de la ciencia moderna manejada en las funciones universitarias. Con esta educación, se considera que respetar tal status es una garantía tendiente a cuidar y reproducir los diferentes mecanismos de ejercicio del poder político.

Baczko (2000) desvela la importancia de la mirada de Marie Jean Antoine Nicolas de Caritat, Marqués de Condorcet (1743-1794), la cual proyecta una educación en donde se muestra la interacción de mujeres en el mundo científico determinado por sus funciones básicas. Con esto, las profesoras están sujetas a la visibilidad legitimada por la distribución del poder patriarcal establecido por la ciencia moderna en sus prácticas universitarias. A su vez, tales actoras tienen fronteras de participación productiva en el mundo político-público-cultural dominado por prácticas masculinas subyugantes determinadas por el sistema sexo/género (Oliva, 2005), aun cuando en la universidad aumenta la cantidad de mujeres intelectuales que ocupan tanto cargos de alto gobierno universitario como la docencia, extensión, servicio, producción e investigación. Todo esto no garantiza el despliegue de una gerencia de funciones universitarias en donde se emerjan intersubjetividades propias de las mujeres. Es importante destacar que ellas, cada vez más, aumentan su protagonismo en la investigación social, dejando de ser actoras de segundo orden en la generación de conocimientos, saberes y tecnologías sociales.

La educación decimonónica resalta que las profesoras son personas políticas en la universidad, quienes deben enfrentar la discriminación social naturalizada en contra de otros escenarios y rutinas de vida fuera de la universidad. Estas actoras se subyugan a sutiles y, a veces, explícitos mensajes-acciones sexistas del colectivo universitario, que desvaloran la capacidad intelectual productiva, el rendimiento laboral, la disposición de contraer compromisos institucionales, la flexibilidad horaria de la jornada laboral. Todo esto se fundamenta en un silenciamiento, ocultamiento, descalificación e incomprensión de un mundo doméstico feminizado y colonizado más para las mujeres que para los hombres. La visión educativa se cimienta en ideas de Pateman (1996), quien estima una educación constituida por el patriarcalismo con el propósito de retomar la visión naturalista. Con esta visión, las mujeres deben criar a sus hijas e hijos ratificando su papel doméstico y subordinado al gran orden de las cosas.

\section{Visión religiosa}


Bowen y Hobson (1979) consideran que desde la época bizantina se fortalece la educación clásica con una modalidad cristiana. Por esto se desvela una educación eclesiástica que refuerza las escuelas catedráticas, así como también se configura una práctica educativa con un protagonismo compartido entre la gubernamentalidad de la Iglesia y el gobierno jurídicolegal del Estado. La educación Ilustrada concibe a las profesoras como agentes sujetadas a las bases político-ideológicas de la Iglesia. Esto ocurre porque su acción profesional e institucional se sustenta en principios religiosos/espirituales de control. Tales principios actúan sobre la trascendencia humana, la salvación, el desarrollo humano, el conocimiento como proceso/producto metafísico, entre otros aspectos. Así, las mujeres intelectuales despliegan intersubjetividades del mundo mágico-religioso sobre todo, de la ideología judeocristiana, como herencia socio-cultural e histórica instalada por la conquista y colonización de imperios europeos. Lo expuesto se concreta en las valoraciones morales emplazadas en las prácticas educativas dentro de la universidad. Existen ejemplos importantes que desvelan la existencia de estas valoraciones, a saber: el desarrollo de prácticas evangelizadoras mediante sus funciones docentes en el nivel de profesionalización, la creación de cátedras libres, como sería la "Cátedra Libre de la Paz" y la "Cátedra Libre Juan Pablo II". A su vez, las profesoras asumen tales principios religiosos/espirituales de control cuando se involucran con las prácticas religiosas legitimadas e institucionalizadas en la estructura organizacional de la universidad. En este caso, en la Universidad del Zulia (Venezuela) existe una parroquia universitaria regentada por la Diócesis de la ciudad de Maracaibo (Venezuela), por medio de esta parroquia, las mujeres intelectuales organizan actividades académicas con fines religiosos y, viceversa.

Posicionado en Baczko (2000), se reconoce la importancia de Charles Maurice de Talleyrand-Périgord (1754-1838), quien expone el surgimiento de una educación en la que las mujeres no realizan cambios de prácticas sociales. Esto define una educación heteronormativa que busca en las profesoras la oposición a la secularización plural, diversa e irreverente de las comunidades universitarias, ya que no aceptan la sexodiversidad. Por otro lado, la educación hace que ellas se contrapongan a la innovación requerida frente a la gerencia y gobierno universitario. Asimismo, incita a que las mujeres intelectuales tengan miedo, desinterés e indisposición al visualizar una amplitud de nuevos escenarios. En consecuencia, se estimula a no asumir libremente su movilidad laboral-institucional hacia otras facultades, universidades nacionales e internacionales.

\section{Visión de la dominación social}

Desde esta visión, la educación obliga a las profesoras a formarse con el ideario de satisfacer a los hombres mediante el compartimiento moral y afectivo, el cual debe recrearse en la formación profesional, sobre todo, de las mujeres. Esta visión las inclina a formarse mediante la subyugación ante las decisiones masculinas impuestas por el gran discurso patriarcal repetido en la cultura normativa de la universidad. Todo esto tiene sentido en Rousseau (1760, citado por Bowen y Hobson, 1979), quien esboza una educación para que los hombres dominen los deseos y las necesidades de las mujeres. Según Amar y Borbón (1790), la educación para la dominación cognitiva suprime los conocimientos. Con esto, el discurso educativo decimonónico visualiza a las profesoras como cómplices profesionales e 
intelectuales, quienes refuerzan la racionalidad cientificista e institucionalista. El discurso educativo, entonces, las coerciona a evadir los saberes populares y tradiciones culturales que narran epistemes-otras.

La educación es un instrumento de disciplina (Vázquez y Pérez, 2012). De esta manera, la instrumentalización formativa orienta a las mujeres intelectuales a asimilar prácticas intersubjetivas de disciplinas científicas impuestas tanto por las profesiones, las epistemes lógicometodológicas como por los modelos gerenciales de la universidad. Por tanto, la educación hace que tales actoras sean agentes reproductoras de la disciplina positivista sobre las consciencias e interacciones sociales del estudiantado. Dicha autora y autor explicitan una educación que controla las identidades de los géneros y las sexualidades, reforzándose al poder de la imagen del varón. Lo manifestado implica una educación heterosexual como un sistema ideológico que las presiona a que repliquen la dominación masculina. Todo esto instaura la discriminación y ocultamiento de identidades plurales-otras de los géneros sexualizados en la universidad.

Pateman (1996) desvela una educación sometida por la subyugación político-filosófica del Estado. Con esta educación subyugada se garantiza la libertad de todos los individuos, se desarrolla la razón y se metodologiza una práctica social, donde la escuela es la institución capaz de proporcionar la formación científica. Por esto, la educación decimonónica invita a las mujeres intelectuales a dibujar una identidad profesional fundamentada en el patriarcado de la racionalidad y tecnología científica. La fuerza de esta visión educacional les incita a apropiarse de una racionalidad ilustrada que se concreta en una tecnologización universitaria en pos de profesionalizar y generar conocimientos apegados a los estándares globales. En consecuencia, la educación moderna es una producción socio-política que impone a las profesoras una visibilidad restringida de su productividad científica, determinada por una identidad heterosexual y fortalecida por una concepción de un Estado heteronormativo. Lo anterior refuerza una educación excluyente con miras a establecer una convivencia limitada para las mujeres (Rousseau, 1973), ya que se destaca la autosegregación y el clasismo intelectualista de las profesoras pautados por la fuerza de un Estado machista, por una cultura científica misógina y por una escuela-universidad tecnocrática e instrumentalista.

En este mismo orden de ideas, se vislumbra una educación más extensa para los hombres que para las mujeres, buscando no alejarlas de su mundo doméstico-familiar (Morales, 1796). En consecuencia, se constituye una educación decimonónica que perpetúa a las mujeres intelectuales a que estén obligadas a alejarse del contexto doméstico. Dicho distanciamiento provoca conflictos en la sostenibilidad emocional de la relación entre la pareja matrimonial y entre hijas e hijos, en la supervisión de la educación filial, en la manutención económica del hogar, debido al pago del servicio de limpieza doméstica, entre otras situaciones. Según Baczko (2000), hay contribuciones históricas importantes en torno al debate de la educación sexista, tales como las de Honoré Gabriel Riquete, Conde de Mirabeau (1749-1791), pues ellas presentan que la educación debe ser para que el hombre esté destinado al mundo económico en el espacio público, mientras que la mujer esté ubicada en el mundo privado. Se contempla, además, una educación para que el hombre realice más actividades públicas, civiles y de asuntos no familiares. Así, pervive una educación ilustrada que subyuga a las profesoras para que estén obligadas a apropiarse de espacios públicos, ubicándose en estructuras de gobierno y gerencia universitaria. De esta manera, se traspolan rutinas y subjetividades propias de su 
vida "privada" a interacciones públicas. Con lo anterior, se logra la doble jornada que implica más trabajo físico, menos ganancia económica, porque ella debe restringir su disponibilidad/ aspiración laboral/económica por atender al hogar.

Desde la mirada de Vázquez y Pérez (2012), la educación rousseauniana es un mecanismo dirigido a domesticar a las mujeres, actúa esto como base de la formación del hombre. La educación en mención presiona, al aceptar su acción responsable de educar tanto a los hombres como a las mujeres de su hogar. Esto les compromete a las siguientes acciones: ejecutar el máximo control sobre las actividades domésticas para que su familia tenga protección, dibujar 'el modelo correcto de madre' y sentir que su proyecto de vida patriarcal tiene aprobación tanto social, ética como moral, a la luz de cánones esperados por las funciones de maternidad y cuidado. Tomàs i Folch (2011) asume una educación reforzadora de la discriminación de género en contra de las mujeres, pues, se establece un conjunto de barreras simbólicas que impiden su desarrollo profesional. La educación decimonónica considera que las profesoras interactúan con obstáculos socio-sígnicos que obstruyen su desarrollo profesional, intelectual e institucional. Las dificultades culturales pueden ser: el cuidado demandado por su padre/ madre y por hijas/hijos quienes pueden padecer de cualquier discapacidad física/cognitiva, la insuficiencia financiera por su estatus en el escalafón profesoral y la dedicación contractual, la recurrencia de una relación sexo-afectiva conflictiva, celópata, agresiva, represiva y no colaborativa con su pareja, la presencia de una limitación de su propio cuerpo, entre otras.

Esta misma autora reconoce que la educación vislumbra al profesorado como un cuerpo político-académico reproductor de estereotipos de géneros; se manifiesta la adecuación de acciones con los valores morales esperados/aceptados en pro de perpetuar un sistema de calificación/ descalificación social. Por tanto, la educación moderna plantea que las profesoras deben replicar estereotipos, más que todo, negativos en cuanto a los géneros de sus acompañantes durante su convivencia universitaria, así como, ante otros colectivos sociales. Ellas están presionadas a generar estereotipos que desvalorizan varios aspectos, a saber: las capacidades físico-intelectuales, las posiciones político-partidistas, las orientacionesidentidades-prácticas sexuales, la realización de actividades político-ideológicas, los modelos profesorales insurgentes e irreverentes que se extralimitan de patrones regulados, de posiciones epistémicas y filosóficas alternas/opuestas a las tradicionales de una disciplina.

La educación fortalece la separación epistémica, óntica e ideológica de lo privado y público, lo cual divide la sociedad civil determinada por el mundo de varones (Pateman, 1996). Desde la lógica heteronormativa, la educación subyuga a las profesoras a que incorporen la educación como una disciplina científica y práctica formativa, como un sistema pragmático que separa el sentido doxo del conocimiento frente al sentido vivido-emergente de los saberes sociales. Así, se excluyen las perspectivas educativas-otras, contextuales y originarias. Todo esto refuerza que la universidad es un espacio público cargado de signos que no puede ser "contaminado" con la simpleza y banalidad del mundo privado. Según Becher (2001), la educación perpetúa fronteras de lenguaje y literatura, lo cual dificulta el diálogo entre diferentes áreas de conocimiento. Además, se refuerza una simbología propia que bloquea la comprensión de otras comunidades. Todo esto rechaza saberes y conocimientos en las prácticas sociales universitarias. La educación es un sometimiento para que las actoras mencionadas desplieguen tradiciones en la producción de conocimiento e interacciones históricas heteronormativas, obligándoles a defender los 
capitales intelectuales de la ciencia moderna. Dichas mujeres requieren crear significados y signos lingüísticos propios de cada disciplina a la que pertenecen en la universidad. Lo expuesto pretende varios objetivos, a saber: ser diferenciadas de otros grupos disciplinares, gestar espacios de poder que controlen la calidad de un conocimiento determinado, instaurar barreras que restringen el diálogo fundamentado tanto en la soberbia epistémica como en la falacia de que poseen la absoluta de verdad.

Para Camps y Giner (1998), la educación tiene un comportamiento cívico basado en la voluntad y esfuerzo en pro de la convivencia. Ambos construyen una ciudadanía cimentada en un sentido común y universal en pro de enraizar una igualdad para una democracia liberal. Dicha educación se funda en normas conductuales que van más allá de formalismos decretados institucionalmente pues, más bien, configuran una convivencia pacífica y solidaria. La educación se cimienta en buenos modales y respeto hacia las personas; reconoce que las profesoras deben transmitir valores positivos, humanistas, teológicos-religiosos y de una democracia románticasuperficial-muy feminizada-e-idealista. Esto hace que ellas mantengan una relación social que origina un supuesto ambiente de bienestar, comodidad, seguridad y satisfacción para los diferentes grupos universitarios en sus prácticas académicas y gerenciales. Dicha imposición de valores hace que ellas se rijan por normas y concepciones morales que determinan, vigilan y castigan su vida sexual-reproductiva, familiar, afectiva-amorosa, profesional y partidista en la universidad. Por eso, se troquela coercitiva y alienadamente un imaginario de perfección humana ante el cual las personas deben tanto visualizarlo, así como encarnarlo, para ser un modelo de ciudadanía idónea que sirva en pro de la educación.

Finalmente, Martínez (2006) muestra una educación cimentada en la declaración "Sobre la enseñanza firme pero amable de los niños" (de Rotterdam, 1528) con la que se supera la bestialidad de la naturaleza humana con la fusión de la civilidad masculina y la espiritualidad cristiana. Esto moldea a un ser humano apto para tener dignidad de ser humano y no animal. Se considera, entonces, que el discurso educativo se consolida en supuestos pedagógicos y psicológicos que obligan a elevar la condición natural, en pro de fortalecer la condición racional. Por esto, el ser humano debe ser más intelecto que animal. De esta manera, la educación decimonónica implica que las mujeres intelectuales incorporen el sentido ideológico dominante de que tal discurso es un mecanismo que civiliza a las personas desde un significado masculino. Lo reflejado intenta que las personas adopten una racionalidad-espiritualidad que mire un modelo de perfección profesional, ética y científica que niega, silencia y castiga la expresión del mundo intuitivo de las profesoras. Así se reconoce la imagen de un hombre (persona genérica) que se vanagloría de su intelecto.

\section{Visión de positivismo social}

La presente visión considera que la educación rousseauniana debe concentrarse en el niño, no en el currículo (contenido) ni en el docente (Bowen y Hobson, 1979). Obsérvese que la educación ilustrada concibe que las mujeres intelectuales siguen sometidas a la tradición escolástica-romántica que obliga a enfocarse en objetos didácticos, epistémicos, tecnológicos, materiales, gerenciales-administrativos constitutivos de la planificación académica. Las profesoras enfatizan más la visión instrumental del currículo y le dan menos importancia 
a otros elementos sistemáticos involucrados en la formación profesional. Todo esto hace que ellas se desconcentren de las fenomenologías de las personas involucradas en las interacciones educativas, con lo cual demuestran más relevancia por el mundo tecnocrático que por el social.

Gil (1996) concibe al profesorado como la comunidad de personas legitimadas para ser expertas y especializadas por el hecho de tener una titulación. Se asume una educación en la que se resalta la figura docente como un modelo de actor masculino, quien sabe, quien -supuestamente- no requiere de nadie para construir conocimientos (Altarejos, IbañezMartín, Jordán y Jover, 2003). En otras palabras, la educación moderna identifica a las profesoras como herederas de una consciencia, titularidad y posición jerárquica-moral, con lo cual se dignifican, valorizan y representan. Dicha transmisión cultural le otorga poder patriarcal en la comunidad pedagógico-disciplinar, científica e institucional. En fin, esto incita a comprenderlas como actoras de primer orden en la producción de conocimientos y saberes, así como también, en la participación activa en la estructura universitaria. Desde la óptica de Follari (2008), la educación es un sistema de mercado proclive a formar personas productoras de todo tipo de capital, quienes deben generar competencias sociales en función de perfiles profesionales-educativos, a partir de los cuales se crea una asignación económica. Se trata, entonces, de un sistema que configura la consciencia para que las personas sean productos rentables. Con todo esto, la educación somete a las mujeres intelectuales mediante una ideología educativa que les obliga a entender a a quienes participan de la formación profesional como personas-objetos que están en proceso de maduración de sus cualidades, en pro de ser productos formados predeterminadamente. Lo evidenciado convierte a las profesoras en objeto-sujeto social apetecible ante la demanda de un mercado laboral. Así, ellas deben replicar un discurso ideológico transmisor de una imagen de que son actoras agencialistas especializadas, quienes deben exponer una personalidad de máquina reproductora de saberes y conocimientos, lo cual se transforma en un capital social útil para la sociedad.

La educación heteronormativa refiere a que las profesoras consideran la opresión de recrear el sometimiento ideológico-panóptico-castrador-lacerante. En efecto, se legitima que la experiencia universitaria debe ser un troquelamiento tortuoso para justificar una templanza tanto psicológica como emocional ante la formación científica. Lo expuesto se vincula con Martínez (2006), quien desvela una visión histórico-clásica de que la educación se cimienta en la valoración positiva de las experiencias fuertes y dolorosas, ya que debe ser una vivencia obligatoria en pro de esbozar al ser humano en su proceso educativo. Dicha autora, inspirada en John Amos Comenius (1592-1670), refleja una educación hacia la inclusión de las mujeres mediante su formación en la lengua (idioma dominante), que trae consigo el fortalecimiento de su formación. Por consiguiente, la educación presiona a las mujeres intelectuales a que subyuguen al estudiantado a interactuar solo con el idioma castellano-español, y así se establece una resistencia para incorporar otros idiomas en la profesionalización. Algunas mujeres mencionadas incluyen otros idiomas dominantes tales como el inglés y el francés, pues ambos son sistemas de comunicación requeridos al profesionalizar en esta Escuela de Educación venezolana. Finalmente, se expone una educación que margina a las mujeres con la intención de que no sean investigadoras de verdades abstractas y especulativas. Con esto, ellas deben apropiarse de prácticas y aplicar principios pensados por los varones reconocidos como científicos. Por tanto, la educación decimonónica obliga a las profesoras a autoexcluirse 
en la edificación de verdades abstractas mediante investigaciones básicas para la educación. Se refuerza, entonces, esta educación burguesa sojuzgada por la ideología opresora que les exige crear conocimiento con una visión pragmática y masculinista.

\section{Conclusiones}

La discusión sobre la educación decimonónica como sistema generador de resistencias concluye que la visión política produce conocimientos apegado a disciplinas cientificistas en las consciencias de mujeres intelectuales y refuerza que la sujeción a la ideología masculina instaura prácticas educativas de autobeneficio del poder patriarcal. Esta visión corporiza signos pro-machistas en la convivencia universitaria y resalta que la apropiación del discurso nacionalista origina discriminación endo-y-exogámica en las prácticas educativas. También acentúa gremialismos racistas a partir de islas disciplinares y subraya el protagonismo de una solidaridad social en las profesoras, como función de sujeción y utilitarismo positivista. Finalmente, la visión separa prácticas identitarias entre lo público-lo privado en la vida cotidiana y fortalece la desigualdad sexista en las funciones universitarias.

Ante tal visión, se requiere que las profesoras desarrollen resistencias en cuanto a instaurar la libertad epistémica-disciplinar, y a propiciar la democratización, equidad e igualdad de beneficios generadores de la producción de conocimientos y saberes a la mayor cantidad de colectivos sociales. También, se espera que desplieguen resistencias para que las mujeres reivindiquen su sentido anti-utilitarista frente al sistema capitalista de la ciencia. Con esto, evitan la reproducción de un rol mecanicista inspirado en el machismo. Es necesario que las profesoras vayan en contra de esta visión al generar resistencias dirigidas a romper prácticas identitarias del patriarcado científico en las funciones universitarias. Las mujeres intelectuales pueden resistirse a fortalecer una cultura discriminativa y excluyente en pro de debilitar el espíritu burgués y elitista de la ciencia moderna, la cual rechaza a quienes no pertenecen a las esferas del poder científico. Por tanto, las mujeres mencionadas deben oponerse a esta visión, pues es urgente crear resistencias tendientes a desbloquear de intersubjetividades y prácticas identitarias provenientes del mundo doméstico hacia el mundo laboral en la universidad, ya que tal exclusión funda un conflicto en la vida cotidiana. En relación con esto, ellas están llamadas a visibilizar resistencias contra la desigualdad sexista expresada en los habitus universitarios. Lo expuesto reduce los indicadores de violencia por efecto de la orientación sexual e identidad de géneros en las rutinas académico-gerenciales.

Desde la visión naturalista, se reflexiona sobre la profesionalización con fines civilizatorios para una sociedad cientificista y heterosexual, que acentúa la educación pragmática y para la minusvalía hacia la otredad en las interacciones sociales de las profesoras e, igualmente, reproduce el ejercicio del poder como instrumento para politizar las funciones universitarias. La visión promueve un protagonismo visible que resalta la figura de mujer emprendedora como símbolo de éxito y poder re-masculinizado y reconoce la discriminación del patriarcado universitario en la filosofía institucional, en la estructura organizativa y funcional.

Después de entender tal visión, es preciso que las profesoras forjen resistencias al cimentar un discurso antiheterosexual. Este discurso vislumbra una civilidad-otra más plural, sensible, situacional e inclusiva, la cual emerge desde una concepción científica 
elaborada por una episteme originada a partir de fenomenologías-experiencias de mujeres y feminidades. Las actoras mencionadas deben demostrar resistencias dirigidas a establecer una educación contra-pragmática fundamentada e interesada en la edificación de nuevos enfoques, concepciones, métodos e interacciones educacionales más feministas. De esta manera, se instaura un discurso educativo centrado en aspectos propios de la trascendencia humana y social, así como en el sentido libertario, democrático de las personas. Se persigue, por tanto, una transformación del ser y quehacer dirigida a una concepción educativa más holística y menos reduccionista-utilitarista. Las profesoras están comprometidas a desplegar resistencias con la finalidad de constituir e implementar una cultura de respeto hacia la diversidad, el reconocimiento de la otredad, la valoración protagónica del ser-hacer desvelada en las identidades y prácticas sociales. Esto es indispensable al consolidar una cultura educativa con miras al activismo compartido no-competitivo, a la inclusión y a ver las cualidades positivas en las interacciones socioproductivas de la universidad. Una de las resistencias importantes que las mujeres intelectuales requieren configurar en sus relaciones productivas es acentuar la intención política y práctica sobre el análisis socio-discursivo de significados, intersubjetividades e interacciones que gestan todo tipo de discriminación, sobre todo las vinculadas al mundo simbólico de los géneros en las estructuras y las funciones esenciales de la universidad. Es fundamental que ellas identifiquen las discriminaciones sutiles y expresas con el propósito de mostrar resistencias que minimicen o destruyan las discriminaciones que afectan los diferentes colectivos humanos.

De forma seguida, las profesoras se encuentran en la oportunidad de consolidar resistencias destinadas a una vigilancia centrada en visualizar los contenidos y formas en que se han venido politizando-partidizando las concepciones, métodos y rutinas de las funciones universitarias. En consecuencia, ellas deben demostrar resistencias que eliminen la partidización heterosexista en la universitaria, con lo cual se reduce la exclusión, alienación y sometimiento con la aplicación del sesgo económico-técnico y jerárquico de los partidos políticos. Por último, esta visión provoca que las profesoras revelen resistencias inclinadas a des-institucionalizar el discurso empresarial que pretende concebir y delimitar a la mujer intelectual. Entonces, es importante que ellas reaccionen con argumentos antipatriarcales y antiagencialistas ante las visiones de ser funcionarias, emprendedoras, apegadas al modelo tanto fordista, taylerista como capitalista. Esta reacción ensambla identidades y prácticas con miras a fundamentar que las profesoras son actoras sociales asumidas desde múltiples formas de ser intelectual y hacer las intelectualidades producidas en el diálogo consistente y complementario entre el mundo académico y el mundo popular-cotidiano.

La visión religiosa replica el discurso religioso sobre las consciencias y prácticas sociales y se opone a la secularización, así como también a la diversidad humana restringiendo identidades plurales de mujeres intelectuales. Esta visión se contrapone a la innovación institucional de tendencias espirituales en la convivencia universitaria y desarrolla el miedo a la amplitud y hacia la desestructuración de límites epistémicos-culturales existentes en discursos hegemónicos de creencia social perpetuados en la universidad. Impulsados por la fuerza de tal visión, se plantea la urgencia de que las mujeres intelectuales desplieguen resistencias en pro de oponerse enérgica, argumentada y democráticamente ante todo proyecto ideológico de adoctrinamiento religioso que se traspola desde las iglesias a la universidad. Es clave, entonces, 
que las profesoras implementen una cultura de protección a la seductora y panóptica idea de dominación emergente desde las religiones sobre las estructuras organizativas, funcionales, así como también hacia las interacciones socioproductivas de los colectivos universitarios. Dicha cultura evidencia resistencias dirigidas a secularizar los modelos epistémicos, filosóficos y políticos en la universidad. Esta cultura busca la diversidad de creencias y prácticas religiosas, en donde no se imponga ningún modelo de conducción del comportamiento humano. En la más aguda o extrema de las situaciones, la cultura secular permite que las profesoras desarrollen resistencias destinadas a eliminar los discursos eclesiásticos con una espiritualidad teocéntrica que regulen, vigilen y castiguen la concepción y materialización de proyectos socio-políticos de una educación diferente a la educación judeocristiana.

Las profesoras están comprometidas a mostrar resistencias tendientes a luchar con proyectos catolicistas e ilustrados que niegan la necesidad y oportunidad de secularizar la gestación de conocimientos y prácticas socio-educativas. Asimismo, las mujeres intelectuales requieren configurar resistencias en pro de combatir ante los proyectos políticos, religiosos e ideológicos conservadores que prohíben, castigan e invisibilizan las prácticas identitarias sexuales propias de discursos anti-heterosexuales generados en la socio-semiótica de la diversidad humana. Es decir, ellas deben contraponerse a energías y acciones que obstruyen la vida democrática en la universidad, impidiendo una educación fundada en la libertad e inclusión. Las profesoras pueden configurar resistencias dirigidas a liberar nociones espirituales y sus prácticas sociales correspondientes en el mundo universitario, como muestra de tolerancia pensada desde una universidad plural de experiencias y perspectivas espirituales. Así pues, las mujeres mencionadas deben desplegar resistencias ante los discursos que imponen la visión monoteísta-católica, lo cual reprime la visión educativa y reduce las diferentes formas de educar en los mundos espirituales. En suma, las profesoras están involucradas en demostrar resistencias desestructuradoras de discursos tradicionales, socio-culturales e históricos y los mecanismos institucionales que configuran e impulsan el miedo ante la ruptura de paradigmas espirituales conservadores y de modelos educativos. Todo esto guarda una correspondencia con el pensamiento filosófico-teológico de religiones que quieren intervenir en la educación universitaria. Por tanto, las mujeres intelectuales deben manifestar resistencias para que junto con las demás personas actoras sean más fortalecidas, seguras e inspiradas en que establecer los cambios socio-espirituales es una oportunidad para diversificar la experiencia humana.

Asimismo, la visión de dominación social estimula la complicidad del patriarcado positivista para controlar las funciones de las profesoras y oprime mediante la heterosexualidad educativa e institucional que recae en la configuración de su ser-hacer. Esta visión invisibiliza la productividad científica alterna-diferente-otra que se opone a la heterosexual y refuerza la subyugación del patriarcado para que las mujeres intelectuales sean visibles en sus diversas identidades y epistemes femeninas. La visión referente a la dominación social demuestra las dificultades existentes en el diálogo en relación con los compromisos entre el mundo político y privado de las mujeres; rechaza identidades y prácticas sociales, supuestamente, propias del mundo privado mediante estereotipos descalificantes e, igualmente, provoca un autoacoplamiento hacia el lenguaje disciplinar en pos de estar en el núcleo del sistema-mundo de la ciencia Ilustrada. Basadas en tal visión, las profesoras deben crear resistencias destinadas 
a combatir las tradiciones institucionales y las prácticas sociales que sustentan su complicidad para reproducir el patriarcado en las estructuras organizativas-funcionales e interacciones socio-productivas universitarias. Las actoras mencionadas están comprometidas a oponerse a las intenciones políticas de fortalecer el pensamiento heterosexual y las prácticas de dominación heteronormativas emergentes desde el interior de las dinámicas universitarias. Todo esto consolida la red automática que activa la discriminación, descalificación, exclusión, sexismo e invisibilización más que todo a las mujeres y a la comunidad sexodiversa en la universidad venezolana.

Las mujeres intelectuales requieren desplegar resistencias en pos de destruir diversas barreras simbólicas, materiales e históricas que obstaculizan o anulan el diálogo sobre las identidades y prácticas sociales entre la esfera pública-cultural-política vs. la esfera privada-doméstica-íntima, lo cual polariza sus vidas cotidianas. En este sentido, ellas pueden visualizar resistencias dirigidas a eliminar significados e interacciones culturales del patriarcado que naturalizan, normatizan e institucionalizan prácticas de dominación. Tales prácticas circulan del mundo público hacia el privado y, viceversa, con la intención de establecer una red de control y un gran orden social de los cuerpos humanos. Con lo expuesto, se docilizan y homogenizan las epistemes educativas, políticas y sociales, así como también, la negación de la pluralidad de posiciones educacionales.

Por otro lado, las profesoras se enfrentan a la demanda de expresar resistencias proclives a oponerse política-epistémicamente frente a la ideología heterosexual que rigidiza, jerarquiza, heterosexualiza y monopoliza las interacciones y los idearios educativos en la profesionalización. Igualmente, ellas pueden contraponerse a tal ideología al instaurar la esclerosis, el sesgo y la homogeneidad de las estructuras en la universidad. De este modo, las mujeres intelectuales desmontan y minimizan la fuerza de dominación masculina mediante resistencias que explicitan la erosividad, inflexibilidad, violencia, exclusión e incapacidad de innovación en las teorías, métodos, vivencias e interpretaciones sobre la educación, lo cual impone el pensamiento machista. Este pensamiento sustenta el espíritu heterosexual sobre la vida docentista cotidiana de las mujeres mencionadas.

A la luz de esta visión, las mujeres intelectuales están invitadas a gestar resistencias dispuestas a destruir sistemas políticos, paradigmáticos e institucionales de las disciplinas positivistas. Tales sistemas se ocupan violentamente de ocultar tanto las diversas, diferentes y alternas formas y contenidos educativo-científicos que producen las profesoras en sus funciones universitarias. Por tanto, las actoras mencionadas están motivadas a institucionalizar resistencias en contra de la hegemonía del modelo científico de la Modernidad e Ilustración, considerado como universal y legítimo al producir conocimientos doxos y dominar los saberes sociales de la vida cotidiana. Frente a dicho modelo heterosexual y patriarcal, ellas deben expresar resistencias luchando por la creación de nuevos modelos oportunos y necesarios. Igualmente, las resistencias tienen la intención de visibilizar sus producciones argumentativas, explicativas, resolutivas e interpretativas frente a los fenómenos sociales. Dichas creaciones deben ser comunicadas a través de diversos paradigmas educacionales antimonocéntricos del conocimiento.

Finalmente, la visión de positivismo social acentúa la despersonalización social y 
robotización del sentido de humanidad en las mujeres intelectuales y fortifica el protagonismo productivo rentable de las profesoras en sus prácticas universitarias. A su vez, construye identidades agencialistas y complacientes ante las demandas sociales en la consciencia de las mujeres intelectuales. Entonces, la visión esboza una educación para oprimir y replicar el sometimiento humano mediante las funciones académicas y destaca la invisibilización de la participación femenina en disciplinas masculinizadas. Sin embargo, las profesoras entran a recrear un discurso masculino de la ciencia, obviando así, su oportunidad de producir conocimientos desde epistemes y experiencias femeninas dirigidas por feminismos. Marcadas por la visión del positivismo social, se reconoce que las profesoras deben manifestar resistencias tendientes a luchar en contra de la despersonalización y robotización de las mujeres. Esta sistematización tecnológica del yo propicia el patriarcado mediante el discurso positivista de la ciencia emplazado en estructuras y discursos fundamentales-ordenadores de la vida social. Las mujeres intelectuales, entonces, están llamadas a romper los mecanismos tecno-científicos que se han naturalizado, normatizado e institucionalizado a través de la educación positivista-cartesiana-ilustrada. Con esto, se consolida una noción de ser humano universal, mecanicista e, igualmente, se bosqueja una sociedad y consciencia social tubular, jerárquica, agresiva, machista e invisibilizadora.

En fin, las mujeres mencionadas están comprometidas a plantear resistencias que desmitifiquen la idealización, relevancia, protagonismo y sentido de superioridad racista reproducido por el discurso de la educación para la productividad rentable de las personas, en especial, en las identidades y prácticas sociales de las profesoras. En suma, ellas deben desvelar resistencias opuestas a discursos educacionales enfocados en configurar modelos de un ser humano centrado en la identidad de la productividad tecno-económica como elemento constitutivo de la personalidad. Supuestamente, tal identidad rentista-competitiva favorece el cambio social de otros enfoques socioeducativos indispensables, pero es importante aclarar que no es el elemento más esencial de los seres humanos. Por eso, las profesoras requieren desarrollar resistencias tendientes a fundamentar modelos identitarios que correspondan con una mirada más holística e inclusiva sobre los seres humanos, con la intención de provocar cambios plurales para la trascendencia en la sociedad.

\section{Referencias}

Aguirre, A. (1995). Etnografía. Metodología cualitativa en la investigación sociocultural. Barcelona, España: Marcombo.

Altarejos, F., Ibáñez-Martin, J., Jordan, J. y Jover, G. (2003). Ética docente. Barcelona, España: Ariel Editorial.

Amar y Borbon, J. (1790). Discurso sobre la educación física y moral de las mujeres. Madrid: Imprenta de Benito Cano.

Baczko, B. (2000). Une Éducation pour la Démocratie. [Una educación para la democracia] Genève, France: Librairie Droz 
Becher, T. (2001). Tribus y territorios académicos. La indagación intelectual y las culturas de las disciplinas. Barcelona: Editorial Gedisa

Berger, P. y Luckmann, T. (1979). La construcción social de la realidad. Buenos Aires, Argentina: Amorrortu Editores.

Bowen, J. y Hobson, P. (1979): Teorías de la educación. Innovaciones importantes en el pensamiento educativo occidental. Ciudad de México, México D.F,: Editorial Limusa

Calonge, S. y Casado, E. (2001). Interacción social comunicativa. Un modelo psicosocial. Caracas, Venezuela: Colección Monografías. Comisión de Estudios de Postgrado. FHEUniversidad Central de Venezuela.

Camps, V. y Giner, S. (1998). Manual de civismo. Bogotá, Colombia: Editorial Ariel.

Contreras, A. (2005). La dimensión fenomenológica de la hermenéutica de Heidegger y Gadamer. En J. Iribarne (Comp.). Fenomenología y literatura. Bogotá: Fondo Editorial Universidad Pedagógica Nacional.

Cray, J. (2008). Las técnicas del observador. Visión y modernidad en el siglo XIX. Barcelona: Ad-Literan $\mathrm{N}^{\circ}$ 4. CENDEAC.

Denzin, N. y Lincoln, Y. (1994). Introduction: Entering the Field of Qualitative Research [Introducción: Entrando al campo de la investigación cualitativa]; En N. Denzin e Y. Lincoln (Eds.) Handbook of Qualitative Research. [Manual de investigación cualitativa]. Londres, Inglaterra: Sage.

de Rotterdam, E. (1529). Elogio de la locura. Madrid: Alianza Editorial.

De Sousa Santos, B. (2004). Reinventar la democracia. Reinventar el Estado. Quito, Ecuador: Ediciones Abya-Yala.

Doménech, M.; Iñiguez, L. y Tirado, F. (jan./jun 2003). George Herbert Mead y la psicología social de los objetos. Psicologia \& Sociedade; 15 (1): 18-36. Associacao Brasilera de Psicologia Social, Universidades Federal de Minas Gerais. Belo Horizonte, Minas Gerais, Brasil. doi: http://dx.doi.org/10.1590/S0102-71822003000100003

Follari, R. (2008). La selva académica. Los silenciados laberintos de los intelectuales. Buenos Aires, Argentina: Ediciones Homosapiens.

Gil, F. (1996). Sociología del profesorado. Barcelona, España: Editorial Ariel Educación. 
Heidegger, M. (1927). Ser y Tiempo. Madrid: Trotta.

LeCompte, M. (1995). Un matrimonio conveniente: Diseño de investigación cualitativa y estándares para la evaluación de programa. Revista Electrónica de Investigación y Evaluación Educativa, 1 (1) Recuperado de http://www.uv.es/relieve/v1/RELIEVEv1n1. $\underline{\text { htm }}$

Martínez, E. (2006). La educación de las mujeres en Venezuela (1840-1912). Caracas, Venezuela: Fondo Editorial de Humanidades. Universidad Central de Venezuela.

Mead, G. H. (1923). Mind, Self and Society. [Mente, Yo y Sociedad]. Chicago, USA: University of Chicago Press.

Meléndez-Ferrer, L. (2015b). La reproducción del discurso patriarcal en la ciencia, como sistema de resistencias para la dominación de las profesoras; En E. Martínez (Ed.) La educación en el cambio de época en América Latina y el Caribe desde las perspectivas pedagógicas. Caracas, Venezuela. Recuperado de http://repositorioslatinoamericanos. uchile.cl/index.php/record/view/820705

Meléndez-Ferrer, L. y González Sulbarán, A. (2015c). Revelación del patriarcado en "La Sirenita" como base para la educación de las mujeres, En E. Martínez (2015) La educación en el cambio de época en América Latina y el Caribe desde las perspectivas pedagógicas. Recuperado de http://saber.ucv.ve/jspui/handle/123456789/11610

Meléndez-Ferrer, L.E. (2015a). Resistencias en prácticas sociales de las profesoras universitarias. (Tesis de doctorado inédita) Facultad de Humanidades y Educación. Universidad del Zulia. Venezuela.

Meléndez-Ferrer, L.E. (2014). Construcciones epistemológicas, ontológicas y tipológicas sobre las resistencias en las prácticas universitarias de las profesoras desde los feminismos. Maracaibo, Venezuela: Facultad de Humanidades y Educación. Universidad del Zulia, Manuscrito inédito.

Meléndez-Ferrer, L.E. (2012). Las resistencias como base epistemológica para la comprensión de las profesoras universitarias en sus prácticas sociales. Maracaibo, Venezuela: Facultad de Humanidades y Educación. Universidad del Zulia, Manuscrito inédito.

Morales, J. I. (1796). Comentario sobre la enseñanza de su hija. Biblioteca Nacional de Valencia, Valencia, España.

Oliva, A. (2005). Debates sobre el género, En C. Amorós y A. de Miguel (Eds): Teoría feminista 
de la Ilustración a la Globalización. De los debates sobre el género al multiculturalismo. (Vol. 3 pp: 13-60) . Madrid, España: Minerva Ediciones.

Pateman, C. (1996). Críticas feministas a la dicotomía público/privado. En C. Castells (Coord.) Perspectivas feministas en teoría política (pp: 31-52). Madrid: Paidos.

Quesada, J. (2003). Otra historia de la filosofía. Barcelona, España: Ariel.

Rodríguez, G.; Gil, J. y García, E. (1996). Metodología de la investigación cualitativa. Málaga: Ediciones Aljibe.

Rousseau, J.J. (1973). Emilio o de la educación. Barcelona: Editorial Fontanella.

Tomás i Folch, M. (Coord.) (2011). La universidad vista desde la perspectiva de género. Estudios sobre el profesorado. Barcelona: Editorial Octaedro.

Vázquez, B. y Pérez, C. (2012). Estado liberal y gubernamentalidad en Venezuela. Caracas, Venezuela: Centro Nacional de Historia. 